\title{
EFFECTS OF CORTISONE ON EXPERIMENTAL

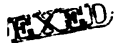 GLOMERULONEPHRITIS
}

BY

\author{
G. TEILUM, H. C. ENGBAEK, N. HARBOE, AND M. SIMONSEN . \\ From the Laboratory for Rheumatic Research of the University Institute of Pathological \\ Anatomy, Copenhagen, and the State Serum Institute and the University \\ Laboratory for Electrophoretic Examinations, Copenhagen
}

(RECEIVED FOR PUBLICATION APRIL 11, 1951)

Earlier attempts to produce glomerulonephritis in immune and sensitized animals with bacterial antigens gave equivocal results. The full picture of an acute glomerulonephritis (type 1 nephritis of Ellis, Evans, and Wilson, 1947) has not been achieved in such experiments. The closest approach in experimental reproduction appears to be the so-called " nephrotoxic nephritis" of Masugi $(1933,1934)$. This is produced by injecting a suspension of renal tissue from one species, e.g., rabbit, into another species, e.g., duck. Serum from the latter sensitized animals, antirabbit-kidney duck serum, when injected into the original species, rabbit, produces glomerular lesions in which epithelial and endothelial proliferations and crescent formation may be prominent, and ultimate fibrosis occur. It has been established that the active agent in the nephrotoxic serum is an organ specific antibody, as it is removed by absorption of the serum by the kidney, but not by other tissues of the species. The pathogenetic relation between nephritis produced by an antibody of the nature of nephrotoxin and the human glomerulonephritis has, however, been obscure, and Masugi himself realized that it would be more convincing to elicit glomerular lesions with an antigen rather than with an antibody. Subsequent examinations of this nature were clearly less convincing than those caused by nephrotoxic serum. The question of the pathogenesis of glomerulonephritis has been elucidated experimentally in the work of Ahlström (1936).

In the experiments reported here marked glomerular lesions were produced, corresponding to the various changes seen in the natural disease, including the type 1 and type 2 nephritis of Ellis.

\section{Incidence of Glomerular Lesions and Albuminuria in Hyperimmunized Rabbits}

In a previous paper the action of cortisone on certain morphological changes observed in rabbits immunized with a formaldehyde-killed Pfeiffer bacillus culture administered in intravenous injections three times a week for many months (Teilum, Engbaek, and Simonsen, 1950) was studied. In all the animals treated with cortisone (20 mg. hypodermically daily for up to six days), a marked regression of the massive accumulations of plasma cells in the spleen was found and further hyalinosis of 
the splenic reticulum proper. Also, it was demonstrated in some cases that cortisone promoted the deposition of a homogeneous substance in the reticulum cells of the perifollicular zone of the spleen.

In such hyperimmunized rabbits in addition to plasma cell accumulations morphological lesions were found in various organs, including glomerular lesions of the kidney ; allergic granulomas and necroses, most frequently in the lungs ; vascular changes similar to periarteritis nodosa ; and marked cortical hyperplasia of the adrenals.

In an unpublished series of 42 immunized rabbits, six showed no changes, 16 slight, and 13 pronounced glomerular changes in the form of deposits in the tufts of a homogeneous substance (Fig. 1), whereas in five cases there were large amounts of hyaline material accumulated in the central parts of the tufts (Fig. 2) corresponding to the highly characteristic lesion which accompanies type 2 nephritis. Lastly, two subjects (2922 and 3197) displayed the typical picture of acute and subacute type 1 nephritis, in which endothelial and epithelial proliferation and crescent formation (Fig. 3) were conspicuous.

In some cases moderate albuminuria and possibly haematuria were also found a few months after immunization. Thus eight out of 69 animals had abnormal constituents in the urine after six months' immunization, but only one out of 85 animals after two months' immunization. After a year only 27 out of 200 rabbits were alive, and five of them had very marked albuminuria but no haematuria.

In the present paper the morphogenetic features of glomerular lesions are studied in hyperimmunized animals with pathological findings in the urine, and corresponding to the human glomerulonephritis types 1 and 2, and the pathogenesis of nephritis and the relation between the types of nephritis mentioned have been illustrated by investigations into the effects of cortisone on the glomerular lesions.

\section{Material and Methods}

All the subjects were white male rabbits of the same strain, and were immunized with a formaldehyde-killed Pfeiffer bacillus culture administered in intravenous injections three times a week (Engbaek, 1949). In eight animals immunized for seven to 16 months and showing severe albuminuria but no unquestionable haematuria, a laparotomy was performed under nembutal anaesthesia seven days after the last injection, with resection of the distal quarter of the spleen and about $1 \mathrm{~g}$. of renal tissue from the left upper renal pole. The microscopical examination of the material removed by means of biopsy showed that only five out of the eight animals displayed marked glomerular changes, whereas accumulations of plasma cells in the spleen were conspicuous in all the subjects.

The five animals with glomerular lesions were given injections of cortisone in the same dose as was employed in previous experiments (Teilum et al., 1950): $20 \mathrm{mg}$. of cortisone acetate "Merck" were administered in one daily hypodermic injection. The injections were begun five days after the operation and were given in series of six days' duration interrupted by one day on which another biopsy of the kidney, and in some cases also of the spleen and the liver, was made. This treatment was continued until the animals died. In the case of one of the animals, which lived unusually long, the dose of cortisone was reduced gradually (compare the report below). The animals which did not display any glomerular changes were not treated with cortisone, but were killed at various times later on. On comparison between biopsy of the spleen 

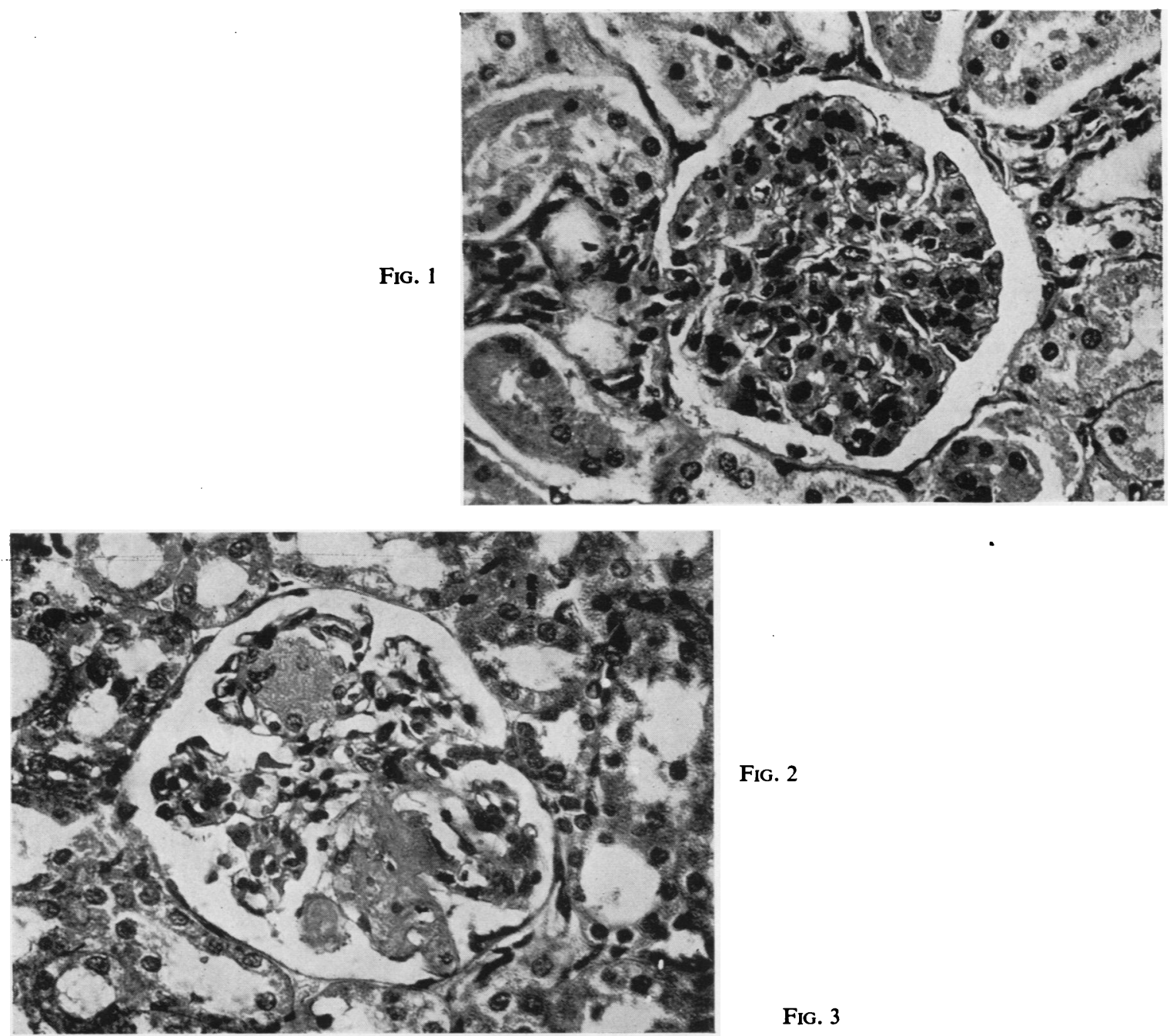

FIG. 2

FIG. 3

FIG. 1.-Deposits in the glomerular tufts of homogeneous prehyaline substance. Haematoxylin and eosin, $\times 400$.

Fig. 2.-Hyaline material accumulated in the central parts of the glomerular tufts corresponding to the lesions in type 2 nephritis. Haematoxylin and eosin, $\times 370$.

FIG. 3.-Typical picture of acute glomerulonephritis (type 1 nephritis) with crescent formation and conspicuous endothelial and epithelial proliferation. Haematoxylin and eosin, $\times 360$.

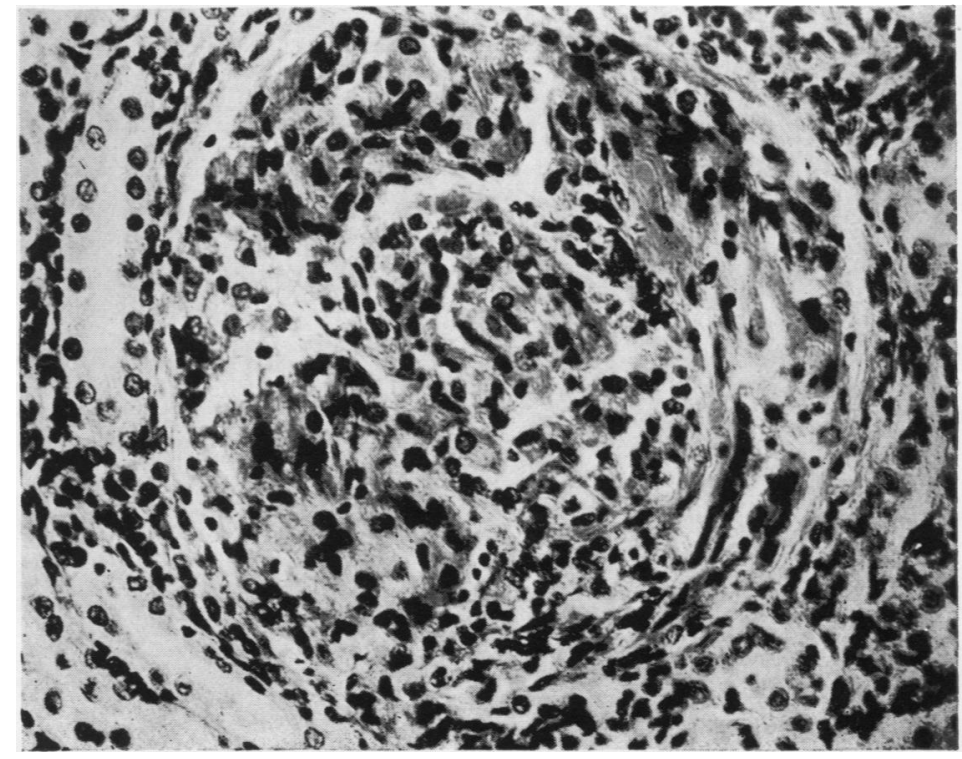


and post-mortem microscopy of the spleen a certain indication of the spontaneous alteration of the splenic changes after discontinuance of the immunization was found.

Serum for determining the total protein (biuret reaction) was taken from all the eight animals a few days after the last immunizing injection, and electrophoretic examination of the serum was made in the five animals with glomerular lesions. Blood urea was determined in the same five animals before the first operation, and in some cases also later (Conway's micromethod). The blood pressure was determined immediately after the first injection of cortisone, and several times later on. Grant and Rothschild's capsule was used for the determination; it was placed over the middle artery of the ear after wiping the ear with xylol. The values stated show the average of three determinations.

\section{Results}

Laboratory data stating the condition of the animals before the first operation and the beginning of the treatment with cortisone are given in Table I. The blood pressure was normal $(60-80 \mathrm{~mm}$. $\mathrm{Hg})$ in all the subjects except one (3785). Of

TABLE I

laboratory and Clinical findings in Animals Injected with Cortisone

\begin{tabular}{|c|c|c|c|c|c|c|c|c|c|}
\hline \multirow{2}{*}{$\begin{array}{l}\text { Rabbit } \\
\text { No. }\end{array}$} & \multirow[t]{2}{*}{ Urine } & \multirow{2}{*}{$\begin{array}{c}\text { Total } \\
\text { Protein } \\
(\%)\end{array}$} & \multicolumn{4}{|c|}{$\frac{\text { Serum Protein Fraction }}{\text { Total Protein }} \times 100$} & \multirow{2}{*}{$\begin{array}{l}\text { Blood } \\
\text { Urea } \\
(\mathrm{mg} . \%)\end{array}$} & \multirow{2}{*}{$\begin{array}{c}\text { Blood } \\
\text { Pressure }\end{array}$} & \multirow{2}{*}{$\begin{array}{l}\text { Survival o } \\
\text { Time } \\
\text { after One } \\
\text { Cortisone } \\
\text { Injection } \\
\text { (days) }\end{array}$} \\
\hline & & & Albumin & $\begin{array}{c}\alpha- \\
\text { globulin }\end{array}$ & $\begin{array}{c}\beta- \\
\text { globulin }\end{array}$ & globulin & & & \\
\hline 3252 & $\begin{array}{c}++ \text { albumin. } \\
\text { A few granu } \\
\text { lated casts } \\
\end{array}$ & $\begin{array}{l}6.4 \\
6.4\end{array}$ & 50.0 & 8.5 & $\begin{array}{c}18.5\left(\beta_{1}\right) \\
2.5\left(\beta_{2}\right)\end{array}$ & 20.5 & 33 & 60 & $21 \frac{2}{\overrightarrow{3}}$ \\
\hline 3321 & $\begin{array}{l}+++ \\
\text { albumin }\end{array}$ & $\begin{array}{l}3.60 \\
3.58\end{array}$ & 26.0 & 16.5 & 37.5 & 20.0 & 38 & & $1 \stackrel{\text { F }}{\stackrel{7}{0}}$ \\
\hline 3564 & $\begin{array}{c}+++ \\
\text { albumin }\end{array}$ & $\begin{array}{l}4.15 \\
4.09 \\
\end{array}$ & 36.5 & 24.5 & 25.5 & 13.5 & 25 & 70 & 17 ㅎํㅇ \\
\hline 3736 & $\begin{array}{l}+++ \\
\text { albumin }\end{array}$ & $\begin{array}{l}6.89 \\
6.83\end{array}$ & 38.5 & 8.5 & 13.5 & 39.5 & 61 & 70 & 11 อิ \\
\hline 3785 & $\begin{array}{c}+++ \\
\text { albumin; a } \\
\text { few granu- } \\
\text { lated casts }\end{array}$ & $\begin{array}{l}6.09 \\
6.07\end{array}$ & 48.0 & 11.0 & 17.0 & 24.0 & 185 & 105 & $46 \quad \begin{array}{l}\text { 음 } \\
\text { 공 } \\
\text { 을. }\end{array}$ \\
\hline $\begin{array}{l}3545 \\
3599 \\
3755 \\
\end{array}$ & $\begin{array}{c}++ \\
++ \\
+\end{array}$ & $\begin{array}{l}5.76 \\
6.05 \\
7.09\end{array}$ & & & & & & & $\begin{array}{l}\text { No o } \\
\text { cortisonen } \\
\text { treatmen? }\end{array}$ \\
\hline $\begin{array}{l}\text { Average of } 53 \text { normal } \\
\text { rabbits }\end{array}$ & & & 61.0 & 8.3 & 13.8 & 16.9 & & & $\underset{0}{0}$ \\
\hline $\begin{array}{l}\text { Average of } 9 \text { hyperim- } \\
\text { munized rabbits } \\
\text { previously report- } \\
\text { ed (Teilum et al., } \\
\text { 1950) }\end{array}$ & & $i$ & 56.5 & 4.4 & 14.9 & 24.3 & & & 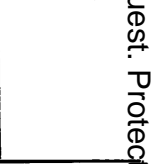 \\
\hline
\end{tabular}


the blood urea values one was unquestionably elevated (the same subject), and another presumably slightly elevated (3736).

\section{Case Reports}

(1) Acute Glomerulonephritis (Type 1 Nephritis) in Rabbit 3785. - On October 8 blood urea was $185 \mathrm{mg}$. \% ; on October 13, biopsy of spleen and left kidney was performed. On October 17 blood pressure was $105 \mathrm{~mm}$. $\mathrm{Hg}$, and between October 17 and $23,20 \mathrm{mg}$. of cortisone was injected daily. On October 24 biopsy of the left kidney and spleen was performed. The abdomen contained more fluid than at the first operation. From October 25 to $30,20 \mathrm{mg}$. of cortisone was given daily. On October 29 blood pressure was 100 . On October 31 biopsy of the right lower renal pole was performed; blood pressure was $100 \mathrm{~mm}$. Between November 1 and 3, $20 \mathrm{mg}$. of cortisone was given daily, and between November 4 and $6,10 \mathrm{mg}$. of cortisone daily. From November 7 to $20,5 \mathrm{mg}$. of cortisone was given daily. On November 9 blood pressure was $80 \mathrm{~mm}$. and blood urea $36 \mathrm{mg}$. \% ; on November 11 blood urea was $32 \mathrm{mg} \%$, and on November 20, $58 \mathrm{mg}$. \%. On November 21 a biopsy was taken of the convexity of the left kidney, of the spleen, and of the right labe of the liver. On November 27 the blood pressure was $45 \mathrm{~mm}$.; urine + albumin, but microscopically nothing abnormal was seen; $\mathrm{Hb}$ (\% Sicca) 55. From November 27 to December $120 \mathrm{mg}$. of cortisone was injected daily. Death occurred on December 2.

At necropsy no oedema or exudates were seen; the spleen was embedded in adhesions ; the liver was very pale, the kidneys enlarged and paler than normally.. The loss of weight from the time of the first operation was $12 \%$. The adrenals weighed $166 \mathrm{mg}$. per $\mathrm{kg}$. of body weight.

Microscopical Observations. - The first biopsy was performed on October 12, 1950, before treatment with cortisone.

The kidney displayed the characteristic picture of acute diffuse glomerulonephritis. The glomeruli were large, prominent, and richly cellular (Fig. 4). Not only proliferation of endothelial and epithelial cells of the tufts was evident, but also proliferation of extracapsular mesenchymal cells, in particular round the afferent arteriole (Fig. 5). The capsular space contained precipitates and scattered synechiae. There were only focal periglomerular and intertubular hyaline changes. Using Unna-Pappenheim's methylgreen-pyronine stain particularly instructive pictures were obtained, which at this stage showed a very pronounced pyroninophilia of the proliferating endothelial and epithelial cells in the glomeruli, the periglomerular and scattered smaller intertubular and perivascular cell proliferations, so that with this stain the glomeruli appeared bright red in contrast to the remaining portion of the renal parenchyma. The epithelium of the parietal capsular layer was also stained in parts with pyronine, and the interstitial renal tissue displayed scattered accumulations of typical plasma cells. In some areas transition from pyroninophilic glomerular cells varying in shape and size to a homogeneous, non-pyroninophilic substance was observed.

The spleen displayed numerous massive accumulations of plasma cells, both around the follicles and in the pulp.

The second biopsy was performed on October 24, 1950, after treatment with cortisone.

The histological picture of the kidney showed striking changes in comparison with biopsy I. The glomeruli were not rich in cells now, but in the tufts there were deposits (Fig. 6) of a homogeneous non-eosinophilic substance which stained a bluish-grey with haematoxylin and eosin and a pale brown with van Gieson-Hansen, and formed larger masses in some of the glomeruli. The latter were completely cleared of cellular proliferation. Unna-Pappenheim staining showed at the same time a pronounced reduction of pyroninophilic substance in the glomeruli and extracapsular accumulations of cells; the 


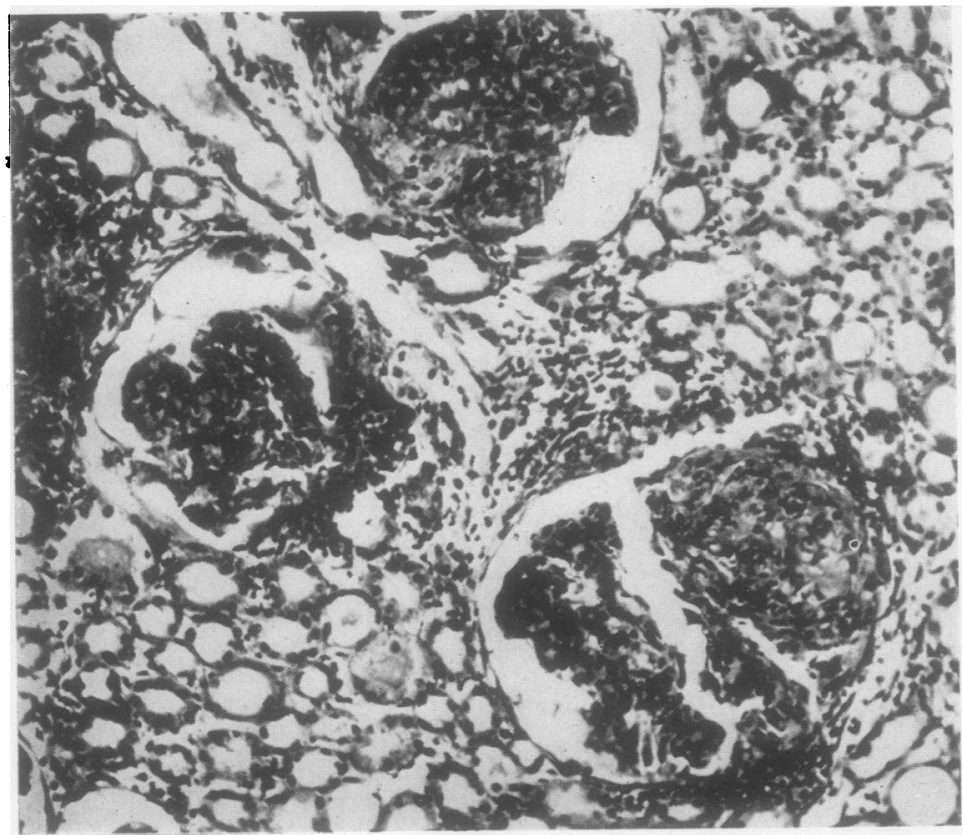

Fig. 4.-Rabbit 3785 with type 1 nephritis before treatment with cortisone. Haematoxylin and eosin, $X$ 180 .

Fig. 5.-Rabbit 3785 before treatment with cortisone. Proliferation of glomerular and extracapsular mesenchymal cells. Haematoxylin and eosin, $\times 370$.

FIG. 4

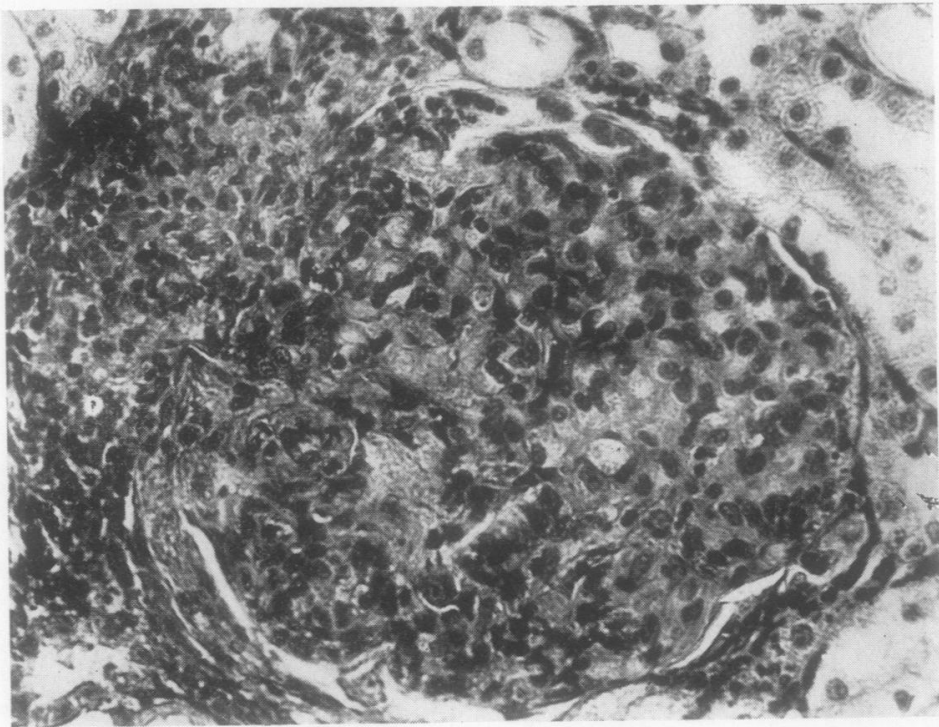

FIG. 5

glomeruli were also much poorer in cells and less conspicuous than before the treatment with cortisone (Fig. 7).

Both the spleen and the kidney displayed a marked regression of the accumulations of plasma cells.

Material was obtained by a third biopsy on October 31, 1950.

In the kidney the homogeneous substance was more compact and more deeply stained with van Gieson staining. Corresponding to the accumulations of pyroninophilic cells found in biopsy I around the vas afferens, there were now in many parts hyaline deposits in the form of local fibrosis, which also appeared around the glomeruli, perivascularly and interstitially, in particular in the medulla corresponding to the localization of 
FIG. 6.-Rabbit 3785. Biopsy II after treatment with cortisone. The cellular proliferation (cf. Figs. 4 and 5) has been replaced by homogeneous deposits similar to the picture of type 2 nephritis. Haematoxylin and eosin, $\times 370$.

FIG. 7.-Rabbit 3785. Biopsy II after treatment with cortisone showing prehyaline changes corresponding to the extracapsular cell proliferation. Haematoxylin and eosin, $X$ 370.

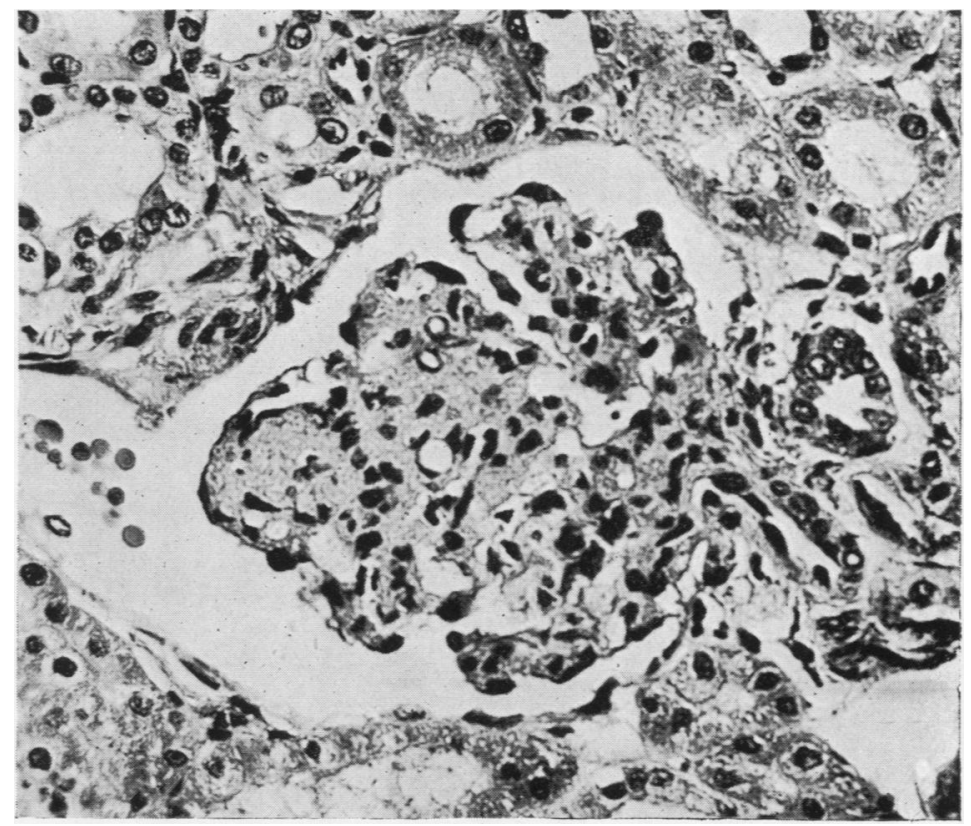

FIG. 6

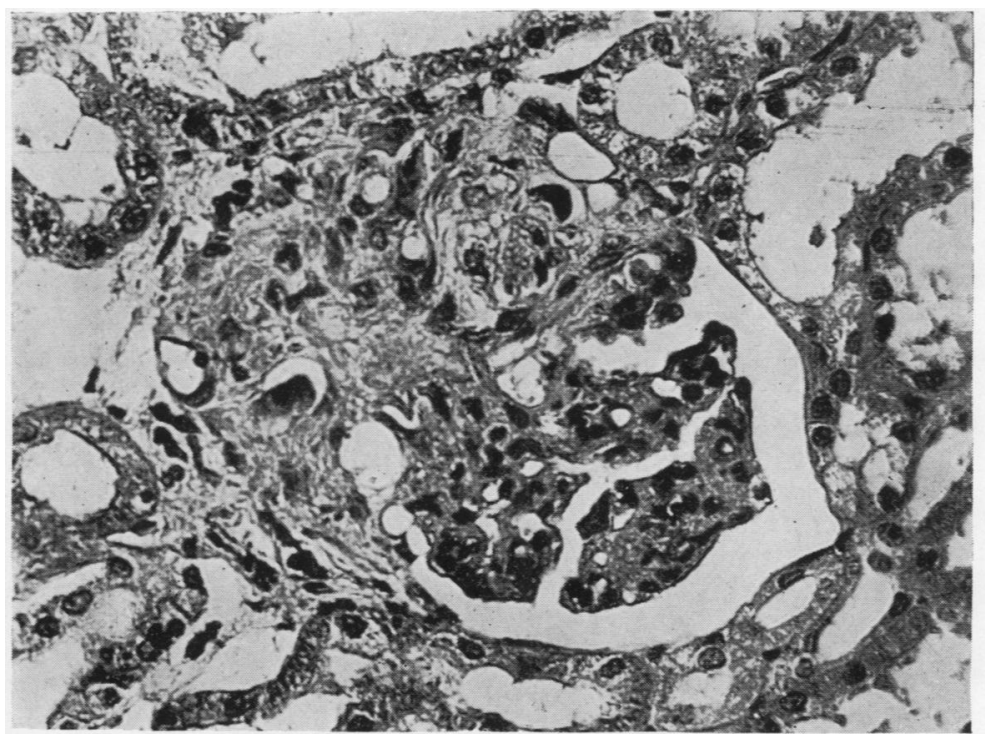

FIG. 7

pyroninophilic mesenchymal cells in biopsy $I$. The pyroninophilia of the glomerular cells had subsided, and only few scattered plasma cells were now found interstitially.

Biopsy IV was performed on November $21,1950$.

The kidney displayed a denser homogeneous substance in the tufts of the glomeruli poor in cells, and stained a deep blue with haematoxylin and eosin. Otherwise there was no essential change from biopsy III. The spleen showed marked perifollicular and perivascular hyalinosis and regression of accumulations of plasma cells. The hepatic cells displayed marked glycogen storage with distended pale cells. In addition there were numerous small sudanophilic vacuoles. 
The necropsy was performed on December 2, 1950.

With van Gieson stain the kidney showed hyalinization in many parts in, and especially around, the glomeruli. The histological picture resembled a so-called type 2 nephritis. No crescents or synechiae were seen. The glomeruli were poor in cells. The spleen showed the same conditions as in biopsy IV. The liver displayed a variegated picture, with a mixture of glycogen-filled and normal cells with granular cytoplasm. The adrenals were moderately hypertrophic

(2) Subchronic Glomerulonephritis (Type 1 Nephritis) in Rabbit 3736. -On October 13 biopsy from the left upper renal pole and distal part of the spleen was performed. On October 17 the blood pressure was $70 \mathrm{~mm}$. $\mathrm{Hg}$, and from that date till October 23 $20 \mathrm{mg}$. of cortisone was injected daily. On October 23 the blood pressure was $70 \mathrm{~mm}$. On October 24 biopsy from the left lower renal pole and proximal part of the spleen was performed. The abdomen contained more fluid than at the first operation. From October 25 to $27,20 \mathrm{mg}$. of cortisone was given daily. Death occurred on October 28 .

At necropsy no oedema or effusions were seen. The loss of weight was $14 \%$ from the first operation. The weight of the suprarenal body was $312 \mathrm{mg}$. per $\mathrm{kg}$. of body weight.

Microscopical Observations.-Biopsy I was performed on October 13, 1950, before treatment with cortisone.

As in rabbit 3785 , the kidney showed a typical so-called type 1 glomerulonephritis, but at a subchronic stage with pronounced epithelial crescents and capsular adhesions (Figs. 8 and 9). The glomeruli were rich in cells, but not so large as in the acute stage. A few of the glomeruli displayed slight hyaline changes, and in most parts hyalinization was seen around the glomeruli and between the tubules with signs of incipient contraction. There were numerous pyroninophilic cells in the glomeruli in the interstices and perivascularly. The spleen displayed accumulations of plasma cells, but no hyalinosis.

Biopsy II was performed on October 24, 1950, after treatment with cortisone.

In the kidney the number of cells was not increased now, and the pyroninophilia of the glomeruli and the crescents had subsided (Fig. 10). A distinct hyalinizing effect was observed on the glomerular tufts, which, with van Gieson staining, displayed fine hyaline deposits and a few hyaline globules.

Necropsy was performed on October 28, 1950.

In the kidney increasing hyalinization of the glomerular tufts and decrease of cellular proliferation was seen, and also hyalinization of extracapsular cellular accumulations. Some capsular adhesions were visible. As in rabbit 3785 , the histological picture after the administration of cortisone corresponded to a nephritis of type 2 , and only the capsular adhesions were reminiscent of the original picture. The pyroninophilia had subsided. A few cells of the parietal capsular layer displayed hyalinization. In the spleen there was severe fibrosis around follicles and vessels. The liver showed a variegated picture; the cells were chiefly without any glycogen storage. The adrenals were more hypertrophic than in the other subjects treated with cortisone, with large lipidic vacuolated cells in the intermediary cortical zone, whereas the cells in the outer part of the fasciculate zone contained no lipid. There was pronounced, diffuse eosinophilic hyperplasia of the anterior lobe of the pituitary, in parts connected with degenerative changes.

(3) Excessive Glomerular Changes comparable to Type 2 Nephritis or Amyloid Nephritis in Rabbit 3564. - On October 13 a biopsy from the left kidney and from the spleen was performed. On October 17 the blood pressure was $70 \mathrm{~mm}$. $\mathbf{H g}$, and from that date until October 23, $20 \mathrm{mg}$. of cortisone was injected daily. On October 23 the blood pressure was $75 \mathrm{~mm}$., and on October 24 a biopsy from the left kidney and the 


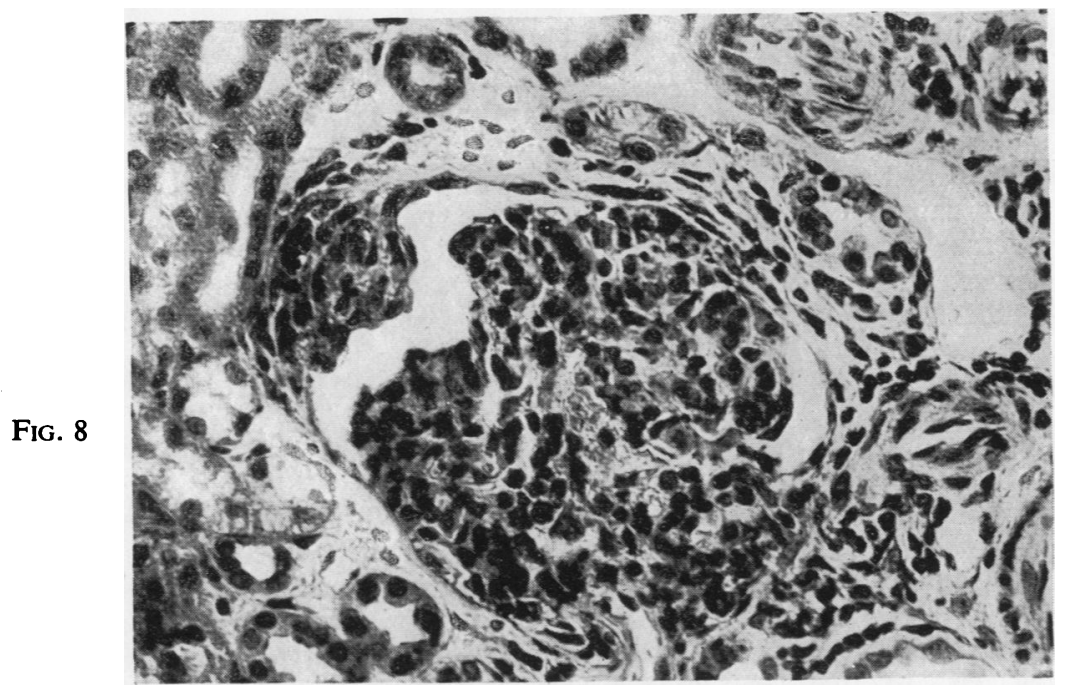

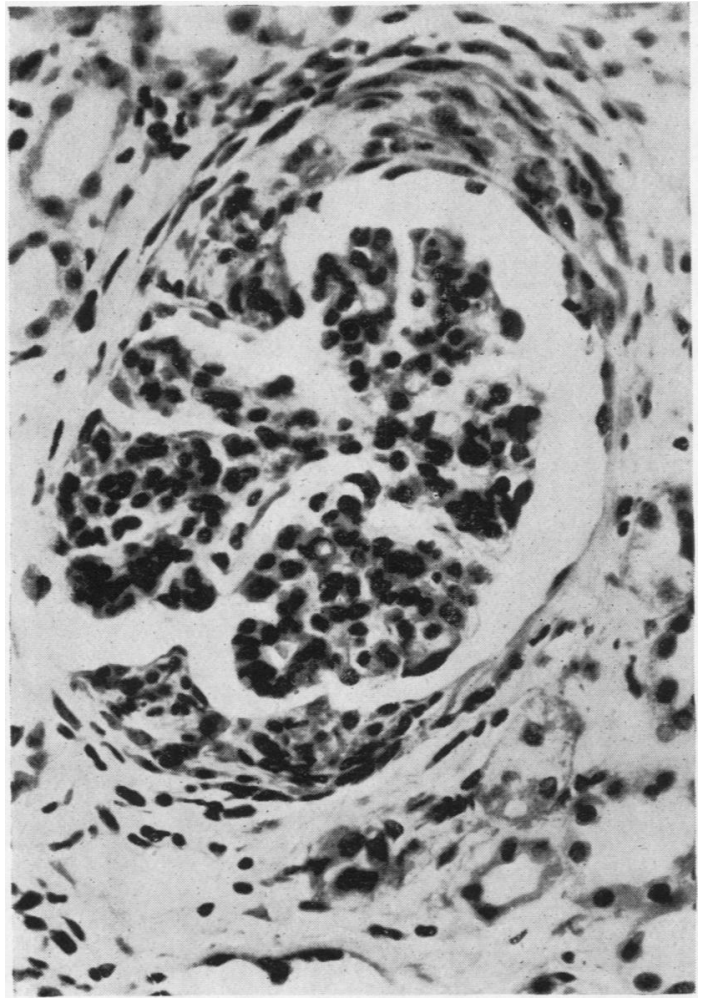

FIG. 9
Fig. 8.-Rabbit 3736. Biopsy I before treatment with cortisone. Subchronic glomerulonephritis (type 1). Cellular glomerulus with crescent formation of parietal capsular layer. Van Gieson, × 370.

FIG. 9.-Rabbit 3736. Biopsy I. Glomerulus showing epithelial proliferation of parietal capsular layer. Van Gieson, $\times 370$.

FIG. 10.-Rabbit 3736. Biopsy II after administration of cortisone. Cellular ptoliferation in glomeruli and synechiae replaced by homogeneous deposits. Van Gieson, X 200.

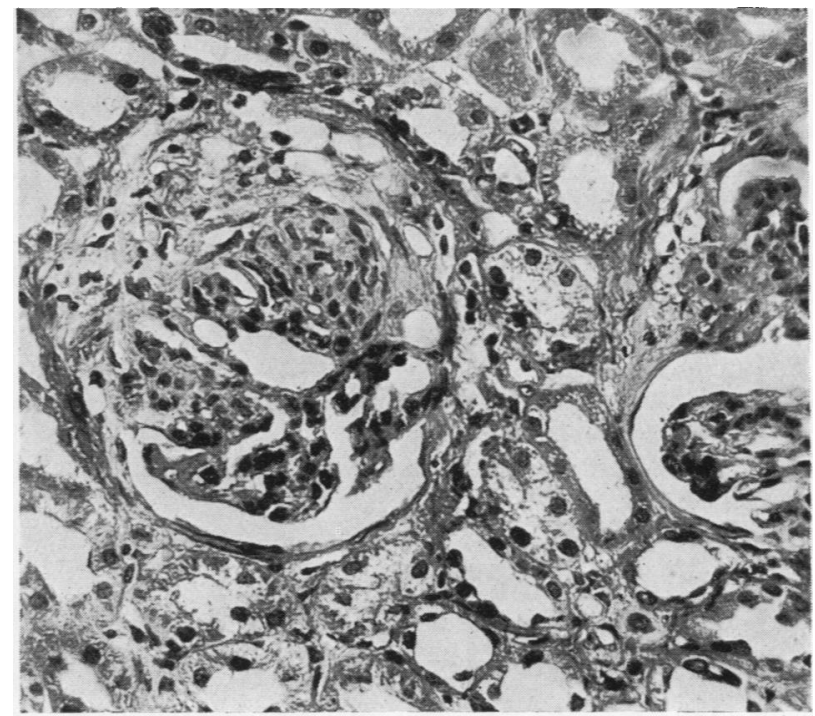

Fig. 10 
spleen was taken; slight ascites was observed. From October 25 to $30,20 \mathrm{mg}$. of cortisone was given daily. On October 29 the blood pressure was $80 \mathrm{~mm}$., and on October $31,60 \mathrm{~mm}$. On October 31 biopsy was taken from the right lower renal pole. Severe ascites and pronounced subserous oedema of the intestine were seen. On November 1 and 2, $20 \mathrm{mg}$. of cortisone was given. On November 2, the urine gave +++ albumin ; microscopy showed nothing abnormal. Death occurred on November 3.

At necropsy severe ascites and bilateral pleural exudation were seen, and atelectases and emphysema in the lungs. The weight of the adrenals was $146 \mathrm{mg}$. per $\mathrm{kg}$. of body weight. The latter had decreased by $10 \%$ since the first operation.

Microscopical Observations.-Biopsy I was performed on October 13, 1950.

In all parts of the kidney there were highly changed glomeruli which were extremely poor in cells, and displayed very large deposits of a homogeneous substance in massive lumps which stained a pale yellow with van Gieson stain (Fig. 11). Scattered in the periphery there were areas with few preserved cells, which in parts were pyroninophilic. The deposits resembled amyloid, but did not seem to be so dense and did not stain with Eden's methyl violet. There were no crescents or capsular adhesions. Interstitially there were scattered, purely hyaline changes, but no contraction. In the spleen there were massive accumulations of plasma cells, and a few small granulomas with pale reticulum cells, negative on amyloid staining.

Biopsy II was performed on October 24, 1950, and III on October 31.

In the kidney the glomeruli had increased in size (compare Figs. 12 and 11), as the homogeneous deposits displayed a further increase, and at the same time the remaining (pyroninophilic) cells of biopsy I had subsided. With van Gieson staining the deposits were pale yellow, and did not stain with methods for amyloid. Dilatation of the tubules was seen in parts. No fibrosis corresponding to the glomeruli but scattered fibrosis in the interstitial tissue was seen, especially around the capillaries.

Necropsy was performed on November 3, when the homogeneous deposits in the glomeruli of the kidney were now seen to be denser and completely resembling amyloid (Fig. 13), staining blue with haematoxylin-eosin stain. Eden's methyl violet stain was faintly positive in parts. Plasma cells in the spleen were decreased in number, with no amyloid deposits. There was no glycogen storage in the liver. A number of lipidic vacuoles was seen. In the adrenals there was lipid vacuolization of the intermediary zone in the cortex as in the preceding case. No unquestionable changes were seen in the pituitary, and no diffuse eosinophilia as in rabbit 3736.

(4) Rabbit 3321.-This animal, which died the day after the institution of treatment with cortisone, displayed widespread subcutaneous oedema and severe ascites in the biopsy. The renal changes were of the same nature as in rabbit 3564, with glomeruli which were poor in cells, showing large homogeneous deposits of a pale yellow in van Gieson staining; Eden's methyl violet staining was negative. No alteration in the renal lesions were found at necropsy. The pituitary displayed no eosinophilic hyperplasia.

(5) Rabbit 3252. - On October 13 a biopsy was taken from the left kidney and the spleen. There was marked ascites. On October 18 the blood pressure was $60 \mathrm{~mm}$. Hg. From October 18 to $24,20 \mathrm{mg}$. of cortisone was injected daily. On October 24 a second biopsy from the left kidney and the spleen was taken. Slight ascites was observed. From October 25 to $30,20 \mathrm{mg}$. of cortisone daily was given. On October 29 the blood pressure was $55 \mathrm{~mm}$., and on October $31,35 \mathrm{~mm}$. On October 31 resection of the right lower renal pole was performed. The ascites remained unchanged. From November 1 to $7,20 \mathrm{mg}$. of cortisone was given daily. On November 2 the urine contained +++ albumin. Microscopy of the urine showed nothing abnormal. On November 8 the animal died. 
Fig. 11.-Rabbit 3564. Biopsy I before administration of cortisone showing very pronounced homogeneous deposits in the glomeruli. Van Gieson, $\times 180$.

Fig. 12.-Rabbit 3564. Biopsy II after administration of cortisone. Glomeruli and deposits considerably increased. Decrease of number of cells in the glomerular tufts. Van Gieson, X 180 .

Fig. 13.-Rabbit 3564 after continued administration of cortisone. Glomeruli show amyloid deposits. Haematoxylin and eosin, $\times 370$.

FIG. 13

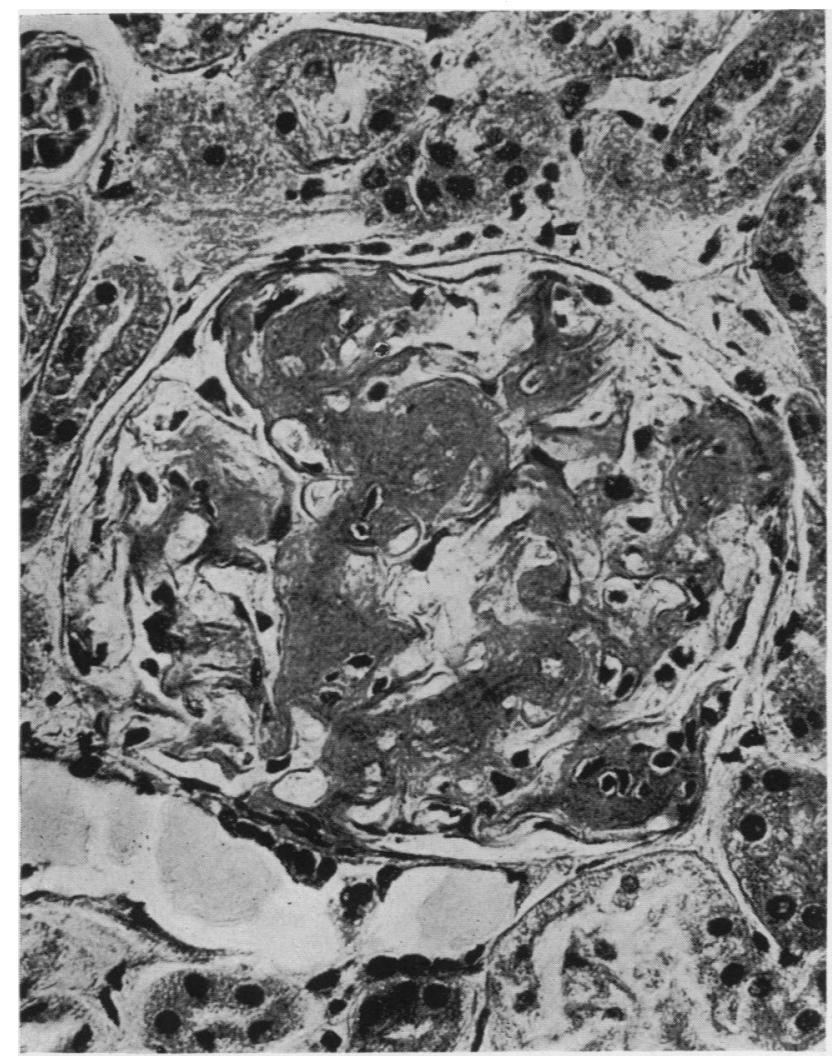

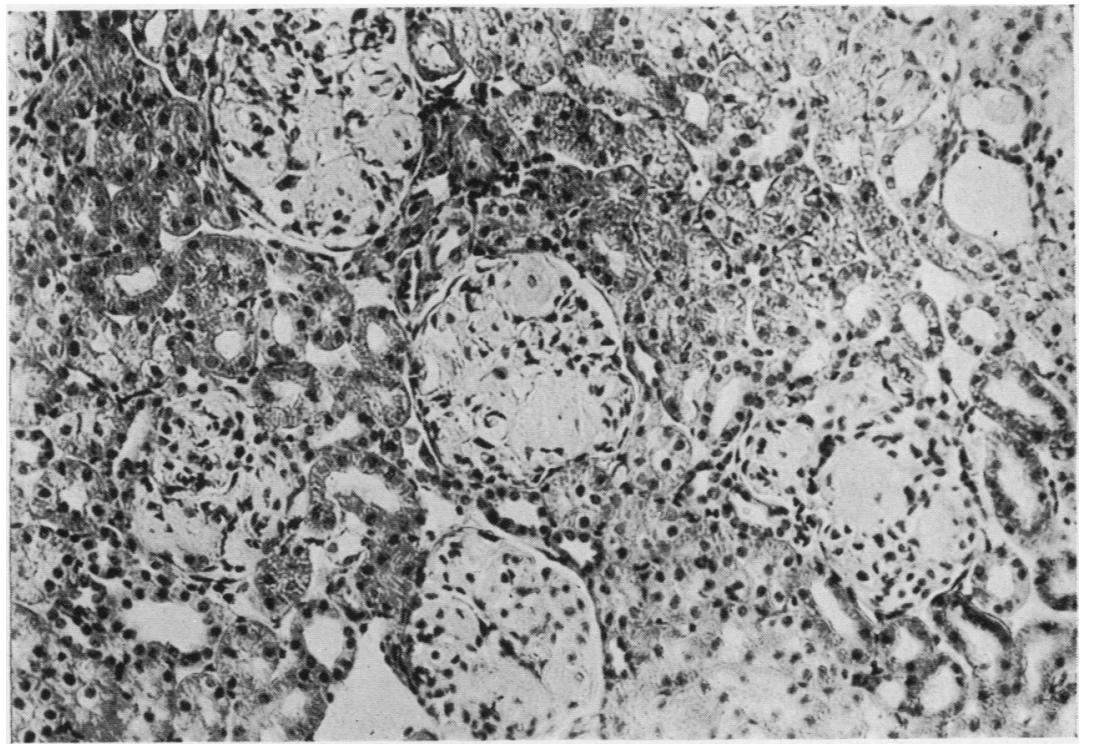

FIG. 11

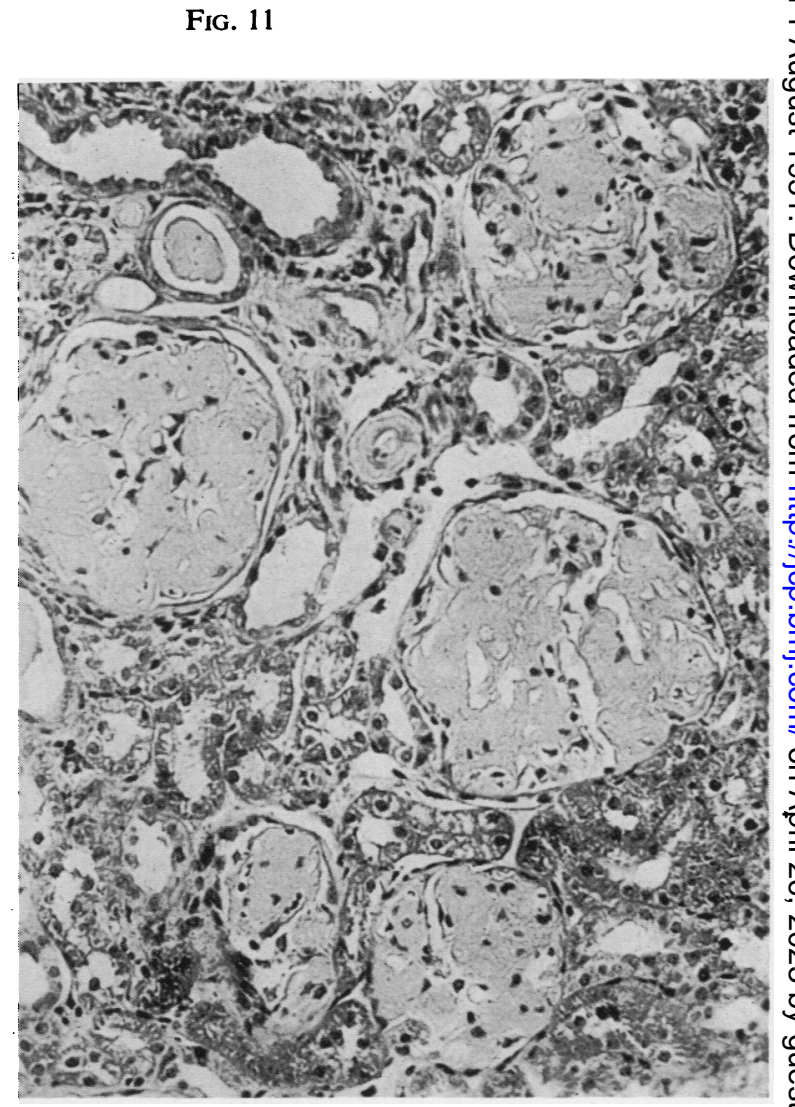

FIG. 12 
Necropsy showed subcutaneous oedema, large oedematous lungs, and pleural exudation in both sides. The loss of weight was $18 \%$ since the first operation, and the weight of the adrenals $98 \mathrm{mg}$. $/ \mathrm{kg}$. of body weight.

Microscopical Observations.-Biopsy I was performed on October 13, 1950.

The kidney displayed focal homogeneous deposits in the glomeruli of the same nature as in the preceding two rabbits (3564 and 3321). In the spleen marked pale yellow prehyaline or preamyloid deposits were seen around the follicles. Eden's methyl violet stain was negative in kidney and spleen.

Biopsy III material (October 31) and the post-mortem examination showed that the deposits in the kidney had increased, and, especially in the spleen, there were widespread amyloid-like changes, still without positive amyloid stain with Eden's methyl violet or Congo red. No hyalinization was observed of the splenic reticulum. The liver showed no glycogen storage. There was no diffuse eosinophilia of the anterior lobe of the pituitary.

The controls $(3545,3599$, and 3755) operated on and not treated with cortisone were killed at the times when, respectively, 3785, 3252, and 3564 died; the former displayed none, or only slight, focal glomerular changes in the first biopsy of the kidney. These controls have been included in order to test a possible spontaneous regression of the changes of the spleen. The glomerular changes in the kidney, like the accumulations of plasma cells in the spleen, had remained unchanged at the post-mortem examination.

\section{Discussion}

The experiments reported illustrate pathogenetic and morphogenetic aspects of glomerulonephritis. In animals hyperimmunized for a prolonged period the full picture of glomerulonephritis was achieved, showing proliferations of endothelial and epithelial cells of the tufts (Figs. 3 to 5), epithelial crescents (Figs. 3, 8, and 9) and, in Case 2, also partial fibrosis. It was quite remarkable that animals treated in the same manner in some cases presented the morphological picture of acute glomerulonephritis (type 1 nephritis), whereas in others glomerulonephritis was found which was comparable to the type 2 nephritis of Ellis, showing the homogeneous prehyaline or hyaline deposits in the glomerular tufts (Fig. 2). The glomerular lesions of this type were diffuse in some of the animals, focal in others. Glomerular changes comparable to the wire loop lesion in lupus erythematosus disseminatus (Fig. 1) and the glomerular hyalinosis and paramyloidosis in sarcoidosis described by Teilum (1951) were also observed (Fig. 11).

Volhard and Fahr (1914), whose classification of renal disease has been universally employed during the last 30 years, considered glomerulonephritis to be a disease with three stages; the acute, the subacute or subchronic, and the chronic stage. During the second stage the disease may present a nephrotic syndrome. From a clinical point of view this classification has suffered from certain defects, as, clinically, typical acute glomerulonephritis generally does not tend to pass on to the nephrotic stage.

A new classification has been put forward by a group of English investigators led by Ellis (Ellis, Evans, and Wilson, 1947). According to these authors "nephritis with nephrotic syndrome" constitutes a special disease which they term glomerulonephritis type 2 , as distinguished from glomerulonephritis type 1 . The latter, which is a disease of children and young adults, is generally considered an 
allergic reaction. The onset is abrupt, accompanied by haematuria. The oedema is not progressive, and $82 \%$ of cases recover completely. Type 2 nephritis, on the other hand, shows a much wider age distribution in man. The onset is insidious, and a history of acute infection is almost entirely lacking. Invariably progressive and persistent oedema is the presenting sign: $95 \%$ of patients die of the disease. The characteristic histological features of the two types correspond to the changes produced in rabbits.

With regard to the different symptomatology and histology of these diseases, reference may be made to Ellis's work and to A. and H. Bergstrand's survey (1949), stressing that the histology undoubtedly supports the theory that nephritis types 1 and 2 are two different diseases.

Even if glomerular lesions comparable to the two types of glomerulonephritis occurred separately in our experiments without showing signs of spontaneous transition from one type to the other, it was of special interest to observe that glomerular lesions of type 1 after the administration of cortisone acetate changed their nature completely in the direction of the changes characteristic of type 2 , a fact which could be ascertained by histological examination of repeated biopsies of the kidneys from the same animals. In cases with pre- or paramyloid deposits the latter showed a further increase in the course of treatment with cortisone and, in one case, transition to amyloidosis. Morphogenetic relations between diffuse types of glomerular lesions, generally considered specific, could thus be ascertained and attributed to limited reactions from mesenchymal cells in the glomerular tufts. In this respect there was a marked parallelism with similar cellular reactions in other mesenchymal tissues under the influence of cortisone (Teilum et al., 1950).

\section{Morphogenetic Studies}

The basic cellular changes were studied after treatment with Unna-Pappenheim's methyl-green-pyronine stain. In the acute type 1 nephritis the proliferating cells of the glomeruli showed a pronounced pyroninophilia, which was also demonstrated in the extracapsular accumulations of cells, in particular around the afferent arteriole (Fig. 5) and in the intertubular pericapillary tissue in the cortex and in the medulla. Sections were incubated with purified ribonuclease $(10 \mathrm{mg}$. per $100 \mathrm{ml}$.) at $p \mathrm{H} 6.7$, or with buffer solution alone for one hour at $37^{\circ} \mathrm{C}$. After treatment with ribonuclease no pyroninophilia could be observed in the cytoplasm, indicating that a synthesis of ribonucleic acid was going on in the glomerular cells as well as in extracapsular mesenchymal cells in the parietal capsular layer, in the walls of the capillaries and interstitially. Many cases of the group not treated with cortisone revealed transition from large, swollen pyroninophilic cells in the tufts and the capsular epithelium to a homogeneous non-pyroninophilic substance.

It was clearly demonstrated in the cortisone experiments that this substance inhibits the pyroninophilia and promotes the transition to homogeneous precipitation (Figs. 6, 7, and 10), causing the histological picture to assume an appearance corresponding to the one found in the subjects with type 2 nephritis. Extracapsularly the number of cells also decreased, so that the accumulation of cells was replaced by a homogeneous substance (Fig. 7). The focal interstitial hyalinosis was apparently of the same pathogenesis. 
The elementary effect on renal changes was thus parallel with the effect of cortisone acetate on the reticulo-endothelial tissue in the spleen previously described and with the inhibitory effect on massive (pyroninophilic) accumulations of plasma cells in the spleen of hyperimmunized rabbits (Teilum et al., 1950).

A genuine hyalinization after the administration of cortisone was found in Case 2 of subchronic nephritis, in which also the proliferation of cells in the crescents decreased considerably. The findings, which we have supplemented with observations from human cases of glomerular hyalinosis, indicate that the hyalinosis of the glomerular tuft cannot be considered a thickening of the basal membrane, but must be looked upon as a product of the proliferating (pyroninophilic) mesenchymal cells. Even if the assumption of a hypersensitivity reaction is not required to explain this cellular change, which may quite naturally be considered analogous with the pyroninophilia in the spleen and in other organs, the occurrence of an increase of the plasma cells, hyperglobulinaemia, and hypersensitivity reactions is, on the other hand, a presenting finding in many conditions (Teilum, 1948 ; Robertson, 1950).

In cases showing excessive glomerular changes comparable with type 2 nephritis (Fig. 11) the treatment with cortisone also produced marked changes in the histological picture. The sparse cellular areas disappeared and further masses of homogeneous precipitates were accumulated in the tufts, causing considerable enlargement and a massive appearance of the glomeruli (Fig. 12). The histological picture suggested amyloid nephrosis, and in some areas a faintly positive reaction for amyloid was obtained in the post-mortem section after treatment by Eden's methyl violet stain for about three weeks (Fig. 13). The clinical and anatomical similarity between glomerulonephritis type 2 and amyloid nephrosis has been pointed out by A. and H. Bergstrand (1949).

In Case 1 of acute glomerulonephritis the laboratory examinations showed a fall of the blood pressure from 105 to $45 \mathrm{~mm}$. $\mathrm{Hg}$, and a fall of the blood urea from 185 to $36 \mathrm{mg}$.\% after treatment with cortisone. The two animals with type 1 nephritis showed an increase of the content of $\gamma$-globulin in the blood before the treatment, whereas two of three animals with a marked nephrotic syndrome showed a decrease of the total protein and an increase of the $\alpha$ - and $\beta$-globulin fractions.

\section{Summary}

In rabbits hyperimmunized with formaldehyde-killed. Pfeiffer bacillus culture given in intravenous injections for periods varying from seven to 16 months the full picture of glomerulonephritis comparable with the natural disease (Ellis's type 1 and type 2 nephritis) was achieved in some cases.

The proliferating cells of the glomeruli in acute glomerulonephritis (type 1) displayed pronounced pyroninophilia, which was abolished by treatment with ribonuclease. The morphological lesions could be attributed to definite elementary cellular reactions controlled by the hormone of the adrenal cortex.

The effect of cortisone was followed by histological examinations of repeated biopsies from the kidney, and in some cases from the spleen and the liver of the same animal. Cortisone caused a marked regression of pyroninophilic cells inside and outside the glomeruli, and promoted a transition to homogeneous precipitates in the tufts, approaching the picture characteristic of type 2 nephritis. 
In cases comparable to type 2 nephritis or paramyloid syndrome, further masses of homogeneous precipitates were accumulated in the tufts, whereas the cellular areas decreased. The histological picture suggested amyloid nephrosis.

After treatment with cortisone one of the animals with acute glomerulonephritis had a marked fall in blood pressure and blood urea. The $\gamma$-globulin was increased before treatment with cortisone was instituted in the animals with type 1 nephritis, whereas cases with a marked nephrotic syndrome showed a decrease of total protein and an increase of the $a$ - and $\beta$-globulin fractions.

\section{REFERENCES}

Ahlström, C. G. (1936). Acta path. microbiol. scand., Suppl. 29.

Bergstrand, A., and Bergstrand, H. (1949). Scand. J. clin. Lab. Invest., $1,334$.

Ellis, Evans, and Wilson (1947). Cited by Hadfield, G., and Garrod, L. P. Recent Advances in Pathology, 5th ed., ch. 13. London. 1947.

Engbaek, H. C. (1949). Undersøgelser over Pfeiffers bacil (with an English summary). Copenhagen. Masugi, M. (1933). Beitr. path. Anat., 91, 82. (1934). Ibid., 92, 429.

Robertson, T. (1950). Amer. J. Med., 9, 315.

Teilum, G. (1948). Amer. J. Path., 24, 389, 409. (1951). Acta path. microbiol. scand., $28,2 \varsigma 4$.

Engbaek, H. C., and Simonsen. M. (1950). Acta endocrinol. Kbh.. 5, 181.

Volhard, F., and Fahr, T. (1914). Die Brightsche Nierenkrankheit. Berlin. 